\title{
Correction of Skin Contour Defects in Leaking Stomas by Filler Injection: A Novel Approach for a Difficult Clinical Problem
}

\author{
Anja K. Weidmann • Firas Al-Niaimi • Calum C. Lyon
}

To view enhanced content go to www.dermtherapy-open.com

Received: May 15, 2014 / Published online: July 9, 2014

(C) The Author(s) 2014. This article is published with open access at Springerlink.com

\section{ABSTRACT}

Background: Stomal leaks can be associated with significant social, psychological and physical morbidity for ostomy patients. Poor fitting of the stoma appliance due to irregularities of skin contours is one cause of stoma leaks which commonly result in secondary irritant dermatitis prompting presentation to a dermatologist. In addition to skin-directed topical therapy and review of stoma appliances, correction of contour defects with intradermal injections of filler

Electronic supplementary material The online version of this article (doi:10.1007/s13555-014-0058-x) contains supplementary material, which is available to authorized users.

A. K. Weidmann

The Dermatology Centre, Salford Royal NHS

Foundation Trust, Stott Lane, Salford M6 8HD, UK

F. Al-Niaimi $(\bowtie)$

St John's Institute of Dermatology, Westminster

Bridge Road, London SE1 7EH, UK

e-mail: firas55@hotmail.com

C. C. Lyon

York Teaching Hospital NHS Foundation Trust, Wigginton Road, York YO31 8HE, UK materials is one possible treatment to improve adhesion and reduce leaks.

Cases: We report eight cases of ostomy patients, who presented with stoma leaks and associated dermatitis, who were treated with intradermal injections of the porcine collagen $\left(\right.$ Permacol $\left.^{\mathrm{TM}}\right)$ or subcutaneous injections of polyacrylamide hydrogel (Aquamid Reconstruction $^{\mathrm{TM}}$ ) for correction of skin contour defects. Resolution or improvement of symptoms was achieved for five patients, and no complications were noted as a result of treatment.

Conclusions: This report represents the largest series of ostomy patients treated for correction of peristomal skin contour defects with injection therapy. Treatment was well tolerated and performed in the outpatient setting under local anesthetic. Attempted correction of peristomal skin contour defects using injection of filler materials represents a potential alternative to surgical intervention and can result in significant benefits for the patient.

Keywords: Collagen; Colostomy; Filler; Ileostomy; Polyacrylamide hydrogel; Porcine collagen; Stoma; Urostomy 


\section{INTRODUCTION}

Indications for stoma formation most commonly comprise; malignancy, inflammatory bowel disease, neurological dysfunction and trauma. Ileostomies, colostomies and urostomies are the most common types of stoma. The number of stoma patients in the United Kingdom (UK) is unknown, but has been estimated to be above 100,000 [1].

Peristomal skin problems are common affecting up to $73 \%$ of ostomates [2]. Peristomal irritant dermatitis is the most frequent skin complication and can be both a cause and a consequence of poor adhesion of stoma appliances associated with leakage of stoma contents [3]. Leakage of stoma contents is common affecting up to $62 \%$ of ostomates and can be associated with considerable social, psychological and physical morbidity $[4,5]$.

Irregularities of the skin surface contours surrounding stoma sites are one cause of poor appliance adhesion and leaks. Such irregularities can arise through remodeling of the skin, pressure from stoma devices, change in body habitus or adjacent scar tissue. Changes to skin surface contours can arise early after stoma formation or as a late complication many years after formation. Regular review of stoma appliances, dressings or use of filler pastes can be used to compensate for alterations in skin surface contours, but are not successful in all cases [6].

Individual case reports have described correction of skin surface contour irregularities by injection of bovine [7] or porcine [8] collagen as a treatment option to improve appliance adhesion and prevent leakage.

We have run a joint stoma-care and dermatology clinic each month in Salford Royal hospital for the last 15 years. It is staffed by the same dermatologist who is regularly involved in their care, 2 stoma nurse specialists and 1 or 2 dermatologists in training. All patients get a full dermatological and ostomy nurse assessment, advice and management plan [2]. There are also weekly open access clinics so that patients can attend without further referral from their own clinician and be seen in the joint clinic if there are problems.

We report a further eight cases of patients, from our clinic with persistent stoma leaks, who were treated with injection of either temporary or permanent filler as a means of correcting skin surface contour defects.

All patients had already tried a variety of appliance modifications without success prior to the use of subcutaneous fillers. These included convex appliances, topical filler pastes (karaya and/or carboxymethylcellulose) or hydrocolloid strips, additional hydrocolloid washers (rings) and barrier films (silicon or acrylate based).

\section{CASE REPORTS}

All procedures followed were in accordance with the ethical standards of the responsible committee on human experimentation (institutional and national) and with the Helsinki Declaration of 1975, as revised in 2000 and 2008. Informed consent was obtained from all patients for being included in the study.

\section{Patient 1}

A 48-year-old woman with Crohn's disease and a long-standing ileostomy presented with persistent peristomal skin irritation and stoma leaks not responsive to change in her stoma appliances or use of filler pastes. On examination, she had a peristomal 
psoriasiform dermatitis and her stoma was sited near a tethered appendectomy scar with peristomal skin depressions.

A total of $12 \mathrm{ml}$ of porcine collagen, Permacol $^{\mathrm{TM}}$ (Tissue Science Laboratories plc, Aldershot, Hampshire, United Kingdom), was injected intradermally during three procedures over a 7-month period. Each procedure was performed under local anesthesia and postprocedural antibiotics were given with ciprofloxacin $250 \mathrm{mg}$ twice daily for 3 days. No complications were noted. Additional topical therapy with betamethasone dipropionate $0.05 \%$ and calcipotriol (Dovobet $^{\circledR}$, Leo Pharmaceuticals, Buckinghamshire, United Kingdom) and localized narrowband UVB was applied with clearance of the dermatitis and resolution of the leaks. She has had no further problems with leakage or dermatitis over the subsequent 4 years.

\section{Patient 2}

A 71-year-old patient with a urostomy formed in 1997 following failed clam cystoplasty presented to dermatology in November 2005 with persistent stoma leaks. On examination, she had peristomal irritant dermatitis and prominent skin guttering at the 3 and 9 o'clock positions around her stoma.

Between March 2006 and August 2010, she underwent repeated intradermal injection of porcine collagen to the affected areas $(\sim 24 \mathrm{ml}$ in total). Volumes of between 1.5 and $3.0 \mathrm{ml}$ were injected to each site as needed under local anesthesia at 2-6 monthly intervals. No additional post-procedural antibiotics were required as the patient was maintained on rotational antibiotic therapy for recurrent urinary tract infections.

Treatment resulted in improvement in leakage and accompanying dermatitis, but with recurrence after 2-3 months. In March 2010, she underwent treatment with subcutaneous injection of $2.5 \mathrm{ml}$ of polyacrylamide hydrogel, Aquamid $^{\mathrm{TM}}$ (Contura UK Ltd, London, United Kingdom), divided between the affected areas with repeated $1 \mathrm{ml}$ injection of one site 3 months later. This did not produce significant improvement and she has reverted to porcine collagen injections to prevent leaks. These continue to be required approximately every 6 months.

Insertion of polyacrylamide hydrogel was followed by post-procedural antibiotics with ciprofloxacin $250 \mathrm{mg}$ twice daily for 3 days. There has been marked improvement in the degree of leakage and she remains under review with repeated treatment with collagen injections every 6 months.

\section{Patient 3}

A 41-year-old patient with a long-standing colostomy and urostomy following treatment for cervical carcinoma in 1988 presented to the stoma clinic in February 2009 with repeated leaks from her colostomy bag. On examination, she had psoriasiform peristomal dermatitis surrounding both stoma sites and a deep skin depression at the $6 \mathrm{o}^{\prime}$ clock position of her colostomy.

Between March 2009 and July 2009, she underwent intradermal injection of $7 \mathrm{ml}$ of porcine collagen in divided doses in addition to topical therapy with betamethasone valerate $0.1 \%$ scalp lotion (Betnovate ${ }^{\circledR}$ scalp lotion, GlaxoSmithKline, Uxbridge, United Kingdom).

Each procedure was performed under local anesthesia and post-procedural antibiotics were given with ciprofloxacin $250 \mathrm{mg}$ twice daily for 3 days. Control of her dermatitis was achieved with maintenance topical therapy, however, 
there was no improvement to the skin depression and she continued to experience leaks. She was referred for surgical refashioning of her stoma.

\section{Patient 4}

In July 2007, a 21-year-old Jehovah's witness, a belief that precludes any transfusion of blood products, with a background diagnosis of Crohn's disease and an ileostomy since 1999 was referred with recurrent stomal leaks. She had already required re-siting of her stoma on more than ten occasions due to recurrent retraction and leakage. On examination, she had bilateral peristomal guttering with significant leakage.

Between September of 2007 and April of 2008, she underwent three intradermal injections of porcine collagen totaling $9 \mathrm{ml}$. Unfortunately, her symptoms did not improve and she was referred for surgical re-siting of her stoma.

\section{Patient 5}

A 64-year-old patient with known PeutzJegher's syndrome and long-standing ileostomy was referred with recurrent stomal leaks due to muscular contraction of the abdominal wall and apparent contractility of the stoma. There was no response to botulinum toxin injection into the stoma musculature. $\mathrm{He}$ was noted to have a pronounced area of guttering at the right lower margin of the stoma which was injected with $2.5 \mathrm{ml}$ of porcine collagen. His symptoms improved and no further treatment was needed. To minimize the risk of further leaks, he has continued to use a hydrocolloid washer under the appliance and has had no further problems after 4 years follow-up.

\section{Patient 6}

A 23-year-old patient with known Crohn's disease and an ileostomy refashioned in 2004 developed recurrent leaks from her stoma $\sim 2$ years after the original surgery. Clinically she had a deep, crescent-shaped depression on the inferior margin of her stoma complicated by excess mucous formation.

She received $1 \mathrm{ml}$ of intradermal porcine collagen to each side of the depression and was given 5 days of post-procedural prophylaxis with erythromycin. Two months after the procedure, there was complete resolution of the depression with significant improvement in symptomology. She had only occasional bag failures after treatment resulting in dermatitis but has not required any further treatment 4 years later.

\section{Patient 7}

A 52-year-old patient with a background history of pyocystitis originally had a urostomy formed in 1999. She was referred in March of 2005, 3 years after formation of her current urostomy, suffering from recurrent leakage. Clinically she had a discernible valley-like circumferential depression around her stoma. This became more pronounced on sitting forward due to muscular tension on the skin.

In total, she received two injections of intradermal porcine collagen totaling $5 \mathrm{ml}$. Although 'plumping up' of the skin was observed post-procedure, this was transient and there was no improvement in her symptoms. She was referred for surgical resiting of her stoma.

\section{Patient 8}

A 28-year-old man with a background history of Hirschsprung's disease presented with recurrent 
leakage from his long-standing ileostomy. His symptoms had required him to give up swimming and were causing him significant distress.

On examination, he had a skin groove medial to his stoma secondary to an adjacent scar. He underwent subcision of the scar under local anesthetic followed 1 week later by subcutaneous injection of $4 \mathrm{ml}$ of polyacrylamide hydrogel. At review after 1 year, he has remained leak-free and been able to recommence regular swimming. He no longer suffers any dermatitis as a result, see Fig. 1.

\section{COMMENT ON CASES}

We considered treatment to be a complete success if the patient no longer suffered bag failures with leakage and subsequent dermatitis and without using any accessory products (patients 1 and 8). Significant improvement was recorded in three others where the patient continued to require some additional treatment either repeated injections (patient 2) or external hydrocolloid washer to maintain bag adhesion (patient 5); or because they have had very occasional bag failure not requiring further collagen injection (patient 6). The cost per syringe for the fillers is $\sim 350$ USD. We have previously described the cost savings made by reducing wasted appliances using botulinum toxin in patients with contractile stomas who presented with up to three bag failures per day (A novel use for botulinum toxin $\mathrm{A}$ in the management of ileostomy and urostomy leaks [9]). We did not formally record frequency of bag failures for patients before and after collagen treatments because we began to use
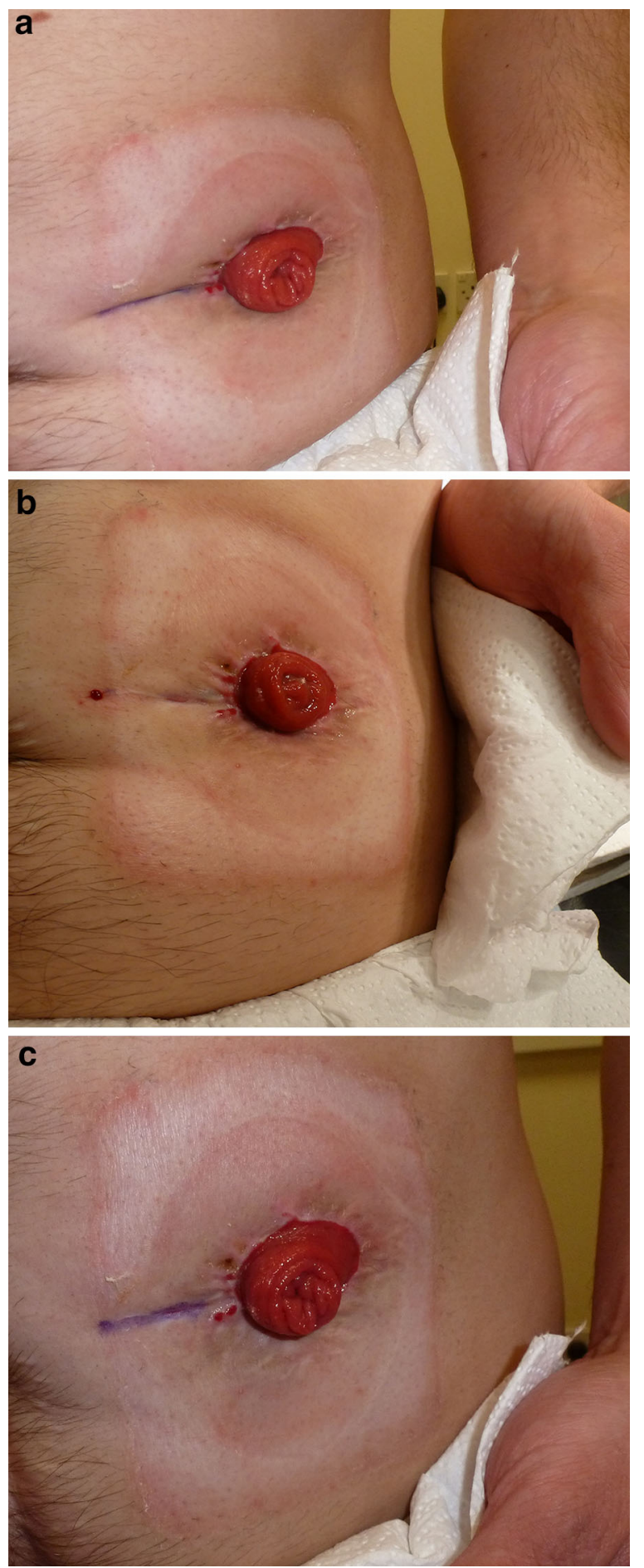

Fig. 1 Case 8 a Pre-treatment medial peristomal groove. b Immediately post-injection of porcine collagen and $\mathbf{c}$ at review 1 year after injection of polyacrylamide hydrogel 
this therapy as an extension of our normal practice using it in other conditions such as subcutaneous fat atrophy. We are therefore not able to be precise about costs in the current cases, however cost benefits are likely to be comparable as, although botulinum toxin is cheaper per unit, more treatments are required and over a longer period of time than for fillers.

\section{DISCUSSION}

Since the nineteenth century, a growing range of autologous and synthetic materials have been used for soft tissue augmentation [10]. Fillers are categorized by origin (autologous, xenologous or synthetic), duration (temporary, permanent or semi-permanent), composition (e.g., collagen, hyaluronic acid, polymethyl methacrylate etc.) and by their intended location within the soft tissues (e.g., subcutaneous or intradermal) [11]. Fillers are used in a wide range of medical and cosmetic procedures including skin rejuvenation, scar correction and treatment of lipoatrophy $[10,12]$.

Porcine collagen is available as an injectable suspension or as solid sheets. The suspension form has been widely used in esthetic soft tissue augmentation and demonstrates a favorable side-effect profile [13]. Clinical use in the treatment of fecal incontinence has been attempted, but is currently of unproven efficacy [14]. Preservation of cosmetic effect depends on successful intradermal injection as subcutaneously placed collagen rapidly dissipates and superficially placed injections in thin skin can cause unsightly blebs [10].

Polyacrylamide hydrogel, an implant which is injected subcutaneously has been in clinical use for over 20 years and appeared under the brand name Aquamid ${ }^{\mathrm{TM}}$ in 2000. It is non-toxic [15] and a 5-year follow-up study by Pallua and
Wolter in patients receiving Polyacrylamide hydrogel for facial soft tissue augmentation showed persistent effect and a favorable safety profile [16]. Minor adverse events following injection included hematomas, pain, discoloration and edema. Infection occurred in four patients $(2 \%)$ of which two were classified as serious. The authors did not recommend prophylactic antibiotics in the setting of facial soft tissue reconstruction [17]. In our experience of treating Parry-Romberg syndrome, Polyacrylamide hydrogel administration as an outpatient procedure was well tolerated and provided sustained improvement to facial contour asymmetry [16].

Autologous fat transfer (AFT) is an alternative to the use of synthetic fillers; however, its use is associated with significant dissipation of the transferred material and a higher rate of complications [18]. AFT has not been described as a treatment for correction of stoma contour defects. Liposuction contouring risks damaging the stoma tract.

Individual case reports describing the use of injected porcine or bovine collagen treatments of peristomal skin contour defects have been described by Smith et al. [8] and Arai et al. [7]. To our knowledge, this report represents the largest single series of patients reported and the first report of the use of permanent fillers for the treatment of stoma leaks.

Smith et al. [8] described a patient who developed leaking of his ileostomy due to an increase in body habitus leading to peristomal striae formation and irregularities of the skin surface. Resolution of the leaks was obtained after one injection of an unspecified amount of porcine collagen under general anesthetic. No post-procedural antibiotics were administered and no complications were noted following the procedure or after 2 years of follow-up. 
Arai et al. [7] described a patient in whom two injections of bovine collagen were applied for correction of paraurostomy skin abnormalities. They applied a small amount of bovine collagen to a test site remote from the area for treatment 1 month before the first procedure and supplied 3 days of postprocedural antibiotics. A total of $5 \mathrm{ml}$ of collagen was injected without anesthetic during two procedures 3 months apart. No adverse events were noted.

Our patients were all long-standing ostomates who had developed skin contour defects months to years after the formation of their stomas. This may have been due to skin remodeling around the stoma or of surrounding scar tissue. Patient characteristics are summarized in Table 1.

In each case, poor appliance adhesion had led to the development of leaks and secondary skin changes. In one case, persistent irritation led to the formation of peristomal psoriatic plaques through Koebnerization. Prevention of stoma leakage led to improvement in the skin and patient quality of life manifesting as confidence to take up social activities such as swimming.

The amount of filler material required varied considerably between cases and some patients required repeated treatments. Unfortunately, not all patients experienced resolution of their symptoms and three cases required surgical refashioning of the stoma. Skin contour defects were exaggerated in obese patients were leaning forward created deep skin folds. We did not find these amenable to treatment with injectable filler therapy because of the large volumes that would be required and the tendency for the material to dissipate (patient 7). However, trial of injection therapy is still a

Table 1 Summary of patient characteristics

\begin{tabular}{|c|c|c|c|c|c|c|}
\hline Patient & $\begin{array}{l}\text { Age at } \\
\text { presentation }\end{array}$ & $\begin{array}{l}\text { Type of } \\
\text { stoma }\end{array}$ & Type of filler & $\begin{array}{l}\text { Number of } \\
\text { injections }\end{array}$ & $\begin{array}{l}\text { Total } \\
\text { volume } \\
(\mathrm{ml})\end{array}$ & Outcome \\
\hline 1 & 48 & Ileostomy & Porcine collagen & 3 & 12 & Resolution of symptoms \\
\hline 2 & 71 & Urostomy & $\begin{array}{l}\text { Porcine collagen and } \\
\text { polyacrylamide } \\
\text { hydrogel }\end{array}$ & $\begin{array}{l}\mathrm{N} / \mathrm{R} \\
2\end{array}$ & $\begin{array}{l}24 \\
3.5\end{array}$ & $\begin{array}{l}\text { Transient improvement only } \\
\text { with polyacrylamide hydrogel. } \\
\text { Patient has continued to } \\
\text { require porcine collagen twice } \\
\text { yearly ( } 1.5 \mathrm{ml} \text { to each of } 2 \\
\text { parastomal depressions) }\end{array}$ \\
\hline 3 & 41 & Colostomy & Porcine collagen & $\mathrm{N} / \mathrm{R}$ & 7 & No improvement \\
\hline 4 & 21 & Ileostomy & Porcine collagen & 3 & 9 & No improvement \\
\hline 5 & 64 & Ileostomy & Porcine collagen & 1 & 2.5 & Resolution of symptoms \\
\hline 6 & 23 & Ileostomy & Porcine collagen & 2 & 2 & Resolution of symptoms \\
\hline 7 & 52 & Urostomy & Porcine collagen & 2 & 5 & No improvement \\
\hline 8 & 28 & Ileostomy & $\begin{array}{l}\text { Polyacrylamide } \\
\text { hydrogel }\end{array}$ & 1 & 4 & Resolution of symptoms \\
\hline
\end{tabular}

$N / R$ Not recorded 
valid recourse particularly in cases such as patient 4 , where religious beliefs, prior surgery or other comorbidities increase the risks of surgery. In cases where improvement was transient, loss of effect could be explained by dissipation of porcine collagen, and substitution of a permanent filler improved efficacy.

Though prophylactic antibiotics are not routinely recommended following the application of fillers for facial soft tissue augmentation, the peristomal environment and potentially serious consequences of infection suggest that post-procedural antibiotics should be considered on a case-bycase basis. No complications were observed from the treatment or as a consequence of antibiotic therapy.

It is our experience that peristomal intradermal or subcutaneous injection of filler materials was well tolerated when performed under local anesthesia in an outpatient setting.

\section{CONCLUSION}

Leakage of stoma contents is a common and potentially disabling problem for ostomates which may result in, or from, disorders of the peristomal skin. Multidisciplinary management of such patients with input from specialist stoma nurses, surgeons and dermatologists should be instituted to optimize appliances and manage skin disease. Irregularities in the peristomal skin surface contours may contribute to poor appliance adhesion and should be sought during evaluation.

This report highlights intradermal injection of fillers as a potential treatment for the correction of skin surface contour defects. Treatment can correct skin contour defects improving appliance adhesion and aiding the resolution of associated skin disease. As such intradermal injection of fillers, such as porcine collagen and polyacrylamide hydrogel, represents a valuable alternative to surgical intervention.

Patient selection is very important, and experience with this small cohort of patients suggests that it is not likely to be effective in those with obese abdomens and/or very deep defects in prominent abdominal folds. In contrast, relatively small, localized defects respond more readily to treatment (see case 8 , Fig. 1).

Dermatologists are well placed to provide such therapy which is heavily dependent on appropriate technique and correct placement of injected material. Our experience suggests that peristomal intradermal or subcutaneous injections are well tolerated when performed under local anesthetic in the outpatient setting.

\section{ACKNOWLEDGMENTS}

No funding or sponsorship was received for this study or publication of this article. All named authors meet the ICMJE criteria for authorship for this manuscript, take responsibility for the integrity of the work as a whole, and have given final approval for the version to be published.

Conflict of interest. AK Weidmann, F AlNiaimi, and CC Lyon declare that they have no conflict of interest.

Compliance with ethics guidelines. All procedures followed were in accordance with the ethical standards of the responsible committee on human experimentation (institutional and national) and with the Helsinki Declaration of 1975 , as revised in 2000 and 2008. Informed consent was 
obtained from all patients for being included in the study.

Open Access. This article is distributed under the terms of the Creative Commons Attribution Noncommercial License which permits any noncommercial use, distribution, and reproduction in any medium, provided the original author(s) and the source are credited.

\section{REFERENCES}

1. Williams J, Ebanks A. Types of stoma and associated surgical procedures. In: Elcoat C, editor. Stoma care nursing. London: Hollister; 2003.

2. Lyon CC, Smith AJ, Griffiths CEM, Beck MH. The spectrum of skin disorders in abdominal stoma patients. Br J Dermatol. 2000;143:1248-60.

3. Nybaek H, Jemac GBE. Skin Problems in stoma patients. JEADV. 2010;24:249-57.

4. Nugent KP, Daniels P, Stewart B, Patankar R, Johnson CD. Quality of life in stoma patients. Dis Colon Rectum. 1999;42(12):1569-74.

5. Richbourg L, Thorpe JM, Rapp CG. Difficulties experienced by the ostomates after hospital discharge. J Wound Ostomy Cont Nurs. 2007;34(1): 70-9.

6. Burch J. Stoma care-related skin problems and solutions. Br J Nurs. 2011;20(21):1358.

7. Arai Y, Okubo K. Correction of dermal contour defect with collagen injection: a simple management technique for difficult stoma care. J Urol. 1999;161:601-2.

8. Smith GHM, Skipworth RJE, Terrace JD, Helal B, Stewart KJ, Anderson DN. Paraileostomy recontouring by collagen sealant injection: a novel approach to one aspect of ileostomy morbidity. Report of a case. Dis Colon Rectum. 2007;50:1719-23.
9. Lyon C, Smith VM. A novel use for botulinum toxin $\mathrm{A}$ in the management of ileostomy and urostomy leaks. Br J Dermatol. 2013;169(S1):6.

10. Matarasso SL, Sadick NS. Soft tissue augmentation. In: Bolognia JL, Jorizzo J, Rapini R, editors. Dermatology. 2nd ed. UK: Mosby Elsevier; 2008. p. 2369-79.

11. Sanchez-Carpintero I, Candelas D, Ruiz-Rodriguez R. Dermal fillers: types, indications and complications. Actas Dermosifiliogr. 2010;101(5): 381-93.

12. Skeie L, Bugge H, Negaard A, Bergersen BM. Large particle hyaluronic acid for the treatment of facial lipoatrophy in HIV-positive patients: 3-year followup study. HIV Med. 2010;11(3):170-7.

13. Saray A. Porcine dermal collagen (Permacol) for facial contour augmentation: preliminary report. Aesthet Plast Surg. 2003;27(5):368-75.

14. Maeda Y, Laurberg S, Norton C. Perianal injectable bulking agents as treatment for faecal incontinence in adults. Cochrane Database Syst Rev 2010;(5): CD007959.

15. Zarini E, Supino R, Pratesi G, et al. Biocompatibility and tissue interactions of a new filler material for medical use. Plast Reconstr Surg. 2004;114(4): 932-42.

16. Al-Niami F, Taylor JA, Lyon CC. Idiopathic hemifacial atrophy treated with permanent polyacrylamide subdermal filler. Dermatol Surg. 2012;38(1):143-5.

17. Pallua N, Wolter TP. A 5-year assessment of safety and aesthetic results after facial soft-tissue augmentation with polyacrylamide hydrogel (Aquamid): a prospective multicentre study of 251 patients. Plast Reconstr Surg. 2010;125(6): 1797-804.

18. Meier JD, Glasgold RA, Glasgold MJ. Autologous fat grafting: long-term evidence of its efficacy in midfacial rejuvenation. Arch Facial Plast Surg. 2009; 11(1):24-8. 